DISTRIBUTION STATEMENT A. Approved for public release; distribution is unlimited.

\title{
Exploring the Thermal Limits of IR-Based Automatic Whale Detection (ETAW)
}

\author{
Olaf Boebel \\ P.O. Box 120161 \\ 27515 Bremerhaven \\ GERMANY \\ phone: +49 (471) 4831-1879 fax: +49 (471) 4831-1797 email: olaf.boebel@awi.de \\ Daniel P. Zitterbart \\ Am alten Hafen 26 \\ 27568 Bremerhaven \\ GERMANY \\ phone: +49 (471) 4831-2212 fax: +49 (471) 4831-1797 email: daniel.zitterbart@awi.de
}

Award Number: N000141310856

http://www.awi.de/en/research/research_divisions/climate_science/observational_oceanography/oceans_acoustic_lab/maps/

\section{LONG-TERM GOALS}

Growing concerns, that aquatic noise produced during naval exercises and offshore seismic surveys may be harmful to marine mammals, have led an increasing number of regulating agencies to request mitigation measures when issuing permits for such surveys in their nations' EEZ. The most common measure is to implement a "marine mammal watch", a team of observers that scans the ship's environs for signs of presence of marine mammals to trigger a shutdown of the hydroacoustic source when marine mammals are entering a predefined exclusion zone.

Marine mammal observers usually scan the ship's environs for whales using binoculars or the naked eye. Sightings mostly rely on spotting a whale's blow, which might rise to a height of several meters but is visible for a few seconds only. Hence, in combination with the whales' prolonged dives, sighting opportunities are rare, which, in addition to the limited field of view and finite attention span of human observers, renders this method personnel-intensive and difficult, even during fair weather and daytime. During darkness it is not feasible.

Our long-term goal is to overcome these difficulties and to develop a reliable, automatic whale detection system for the full range of oceanic environmental conditions (wind, sea surface temperature) and species. To this end, we developed a ship-based thermal imaging system for automated marine mammal detection, consisting of an actively stabilized, spinning IR camera and an algorithm that detects whale blows on the basis of their thermal signature. So far, this technology has been tailored to and tested under cold (SST $<10^{\circ} \mathrm{C}$ ) water conditions only, as this is where the technology was expected to perform best. To adapt the technology to warmer environments and to test its performance there is the specific goal of this proposal. 


\section{Report Documentation Page}

Form Approved

OMB No. 0704-0188

Public reporting burden for the collection of information is estimated to average 1 hour per response, including the time for reviewing instructions, searching existing data sources, gathering and maintaining the data needed, and completing and reviewing the collection of information. Send comments regarding this burden estimate or any other aspect of this collection of information,

including suggestions for reducing this burden, to Washington Headquarters Services, Directorate for Information Operations and Reports, 1215 Jefferson Davis Highway, Suite 1204, Arlington

VA 22202-4302. Respondents should be aware that notwithstanding any other provision of law, no person shall be subject to a penalty for failing to comply with a collection of information if it

does not display a currently valid OMB control number.

\begin{tabular}{|c|c|c|}
\hline $\begin{array}{l}\text { 1. REPORT DATE } \\
\text { 30 SEP } 2014\end{array}$ & 2. REPORT TYPE & $\begin{array}{l}\text { 3. DATES COVERED } \\
\mathbf{0 0 - 0 0 - 2 0 1 4} \text { to 00-00-2014 }\end{array}$ \\
\hline \multirow{3}{*}{\multicolumn{2}{|c|}{$\begin{array}{l}\text { Exploring the Thermal Limits of IR-Based Automatic Whale Detection } \\
\text { (ETAW) }\end{array}$}} & 5a. CONTRACT NUMBER \\
\hline & & 5b. GRANT NUMBER \\
\hline & & 5c. PROGRAM ELEMENT NUMBER \\
\hline \multirow{3}{*}{\multicolumn{2}{|c|}{ 6. AUTHOR(S) }} & 5d. PROJECT NUMBER \\
\hline & & 5e. TASK NUMBER \\
\hline & & 5f. WORK UNIT NUMBER \\
\hline \multicolumn{2}{|c|}{$\begin{array}{l}\text { 7. PERFORMING ORGANIZATION NAME(S) AND ADDRESS(ES) } \\
\text { Alfred Wegener Institute ,P.O. Box 120161,27515 Bremerhaven } \\
\text { Germany, }\end{array}$} & $\begin{array}{l}\text { 8. PERFORMING ORGANIZATION } \\
\text { REPORT NUMBER }\end{array}$ \\
\hline \multirow{2}{*}{\multicolumn{2}{|c|}{ 9. SPONSORING/MONITORING AGENCY NAME(S) AND ADDRESS(ES) }} & 10. SPONSOR/MONITOR'S ACRONYM(S) \\
\hline & & $\begin{array}{l}\text { 11. SPONSOR/MONITOR'S REPORT } \\
\text { NUMBER(S) }\end{array}$ \\
\hline
\end{tabular}

12. DISTRIBUTION/AVAILABILITY STATEMENT

Approved for public release; distribution unlimited

13. SUPPLEMENTARY NOTES

14. ABSTRACT

15. SUBJECT TERMS

16. SECURITY CLASSIFICATION OF:

\begin{tabular}{c|c|c}
$\begin{array}{c}\text { a. REPORT } \\
\text { unclassified }\end{array}$ & $\begin{array}{c}\text { b. ABSTRACT } \\
\text { unclassified }\end{array}$ & $\begin{array}{c}\text { c. THIS PAGE } \\
\text { unclassified }\end{array}$
\end{tabular}

17. LIMITATION OF ABSTRACT

Same as

Report (SAR)
18. NUMBER 19a. NAME OF

OF PAGES RESPONSIBLE PERSON

6 


\section{OBJECTIVES}

This project aims at a cost-efficient test of the thermal limits of the abovementioned IR based automatic whale detection technology by attempting to capture whale spouts during the northward humpback whale migration, which occurs annually rather close to shore near North Stradbroke Island, Queensland, Australia. Based on the collected data, detector/classifier optimization shall be performed and ensuing system performance be tested by subsequent comparisons with concurrent visual observations.

\section{APPROACH}

By obtaining continuous IR video footage during two successive northward humpback whale migrations and collecting concurrent independent (double blind) visual observations (modified cue counting), a data base will be created to:

Determine the performance of the imaging device in warm waters;

- Determine the performance of the existing automatic detector in warm waters;

- Develop optimized auto-detection algorithms for the warm water realm;

- Determine the performance of the optimized detector in warm waters;

- Generate additional baseline data on locomotive behavior of migrating humpbacks (providing the proposed technology proves technically feasible);

- $\quad$ Generate, for the first time, data on night time humpback migration; (providing the proposed technology proves technically feasible);

At AWI, key individuals for this project are Daniel Zitterbart, overlooking the system development, and Elke Burkhardt, overlooking the concurrent sighting data acquisition. The field activities will be supported by Mike Noad, University of Queensland, who has organized many whale surveys off North Stradbroke Island.

\section{WORK COMPLETED}

The 2014 field season was conducted on North Stradbroke Island, Queensland, Australia between 06.06.2014 and 20.07.2014, with a primary data collection period from 14.06.2014 untill 14.07.2014. The main aim for the 2014 field season was to collect IR video footage of blowing whales, whilst concurrently recording their position with visual observations through a theodolite. We deployed a team of 2 (IR technology) plus 6 (visual observers), with additional local support.

The FIRST thermal imager was operated for total of $854 \mathrm{~h}$ ( 35 days), with 783h of IR-data having been recorded. Theodolite measurements of whales were conducted (as part of different protocols, see table below) for a total of $170 \mathrm{~h}$ distributed across this period during daytime. Depending on the research question under investigation, different recording protocols were used, involving 2-4 observers. MMOlike observation (i.e. observations conducted as if for mitigation purposes during a ship-based hydroacoustic survey using hand held binoculars and the unaided eye) were conducted for about $50 \mathrm{~h}$ by an independent team of observers on 6 days. 
The water temperature varied between 22 and $24^{\circ} \mathrm{C}$.

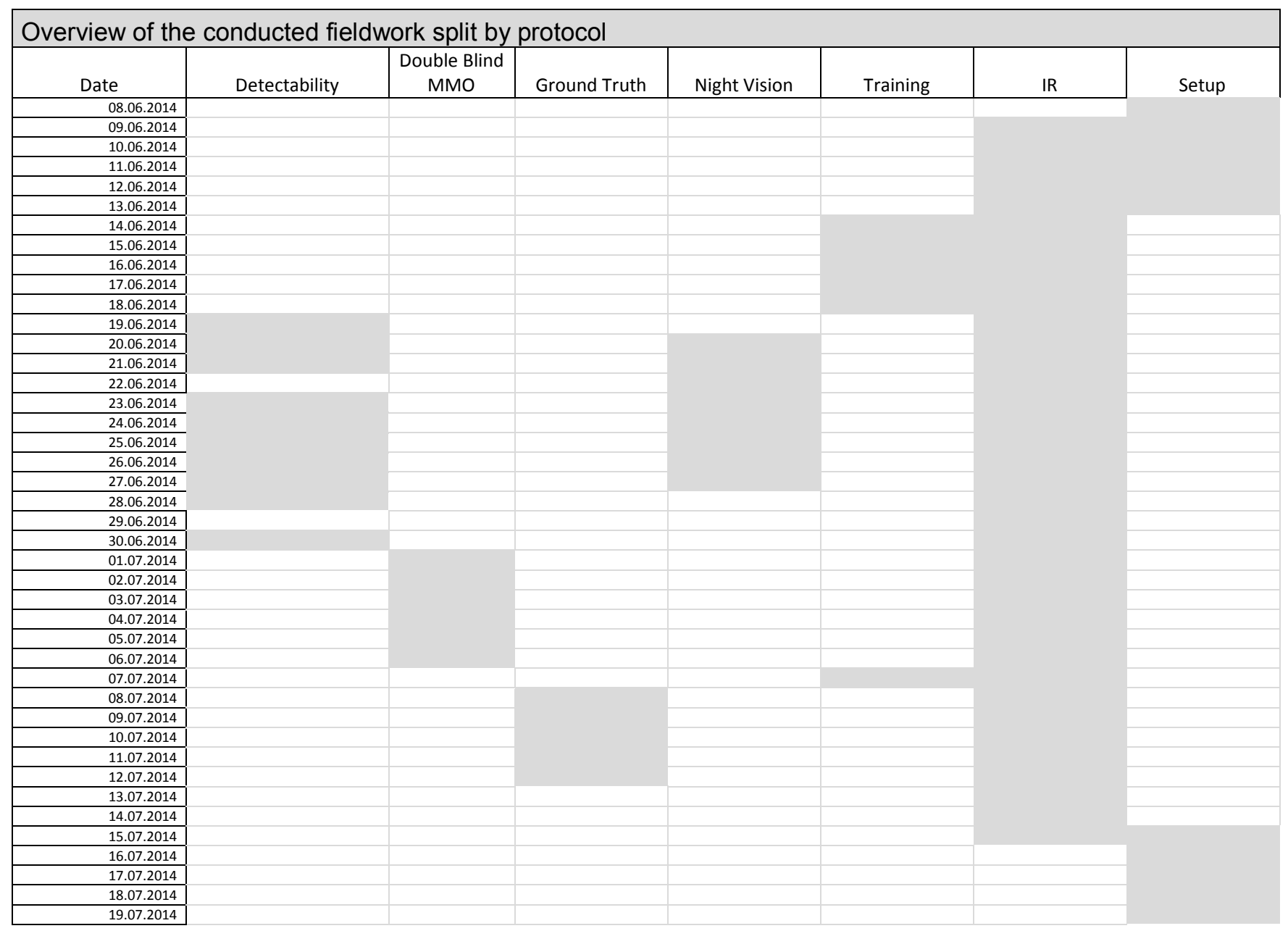

\section{RESULTS}

The primary goal of this field season was to acquire sufficient data to be able to train the SVM (support vector machine) of the automatic whale detection algorithm under warm water conditions. This goal (the collection of sufficient data) has been fully achieved. In a first screening of the IR imagery, we visually identified 2330 cues (mostly blows) in a total of 511 encounters (pods). The high abundance of blows/whales also allowed allocating 6 days to acquire a first data set for (double blind) visual-MMO/IR comparisons.

Generally, the data shows that within $2 \mathrm{~km}$ of the sensor more than $90 \%$ of the observed pods could also be detected by visual screening of the IR footage on computer displays. On occasion, whales were detectable at distances of up to $10 \mathrm{~km}$. The observers considered the detectability of blows in the IR to generally be better during night than during the day. This is probably due to a reduction of the overall contrast in the images during night time due to the absence of relections of sunlight. Glare, i.e. the reflection of the sun on the sea surface, is a problem for marine mammal observations. The probability to detect a surfacing marine mammal in sea patches with glare is practically nil. The angle 
of sea surface which is not observable by an MMO is dependend on the suns position. IR imaging is also impeded by glare, but to a much lesser extent. We found that while the visual observations are not possible in an angular section of $15^{\circ}-25^{\circ}$, IR is impeded much less by glare with $5^{\circ}-7^{\circ}$ degrees of non-observable section.

$153^{\circ} 33^{\prime} 45^{\prime \prime} \mathrm{E}$

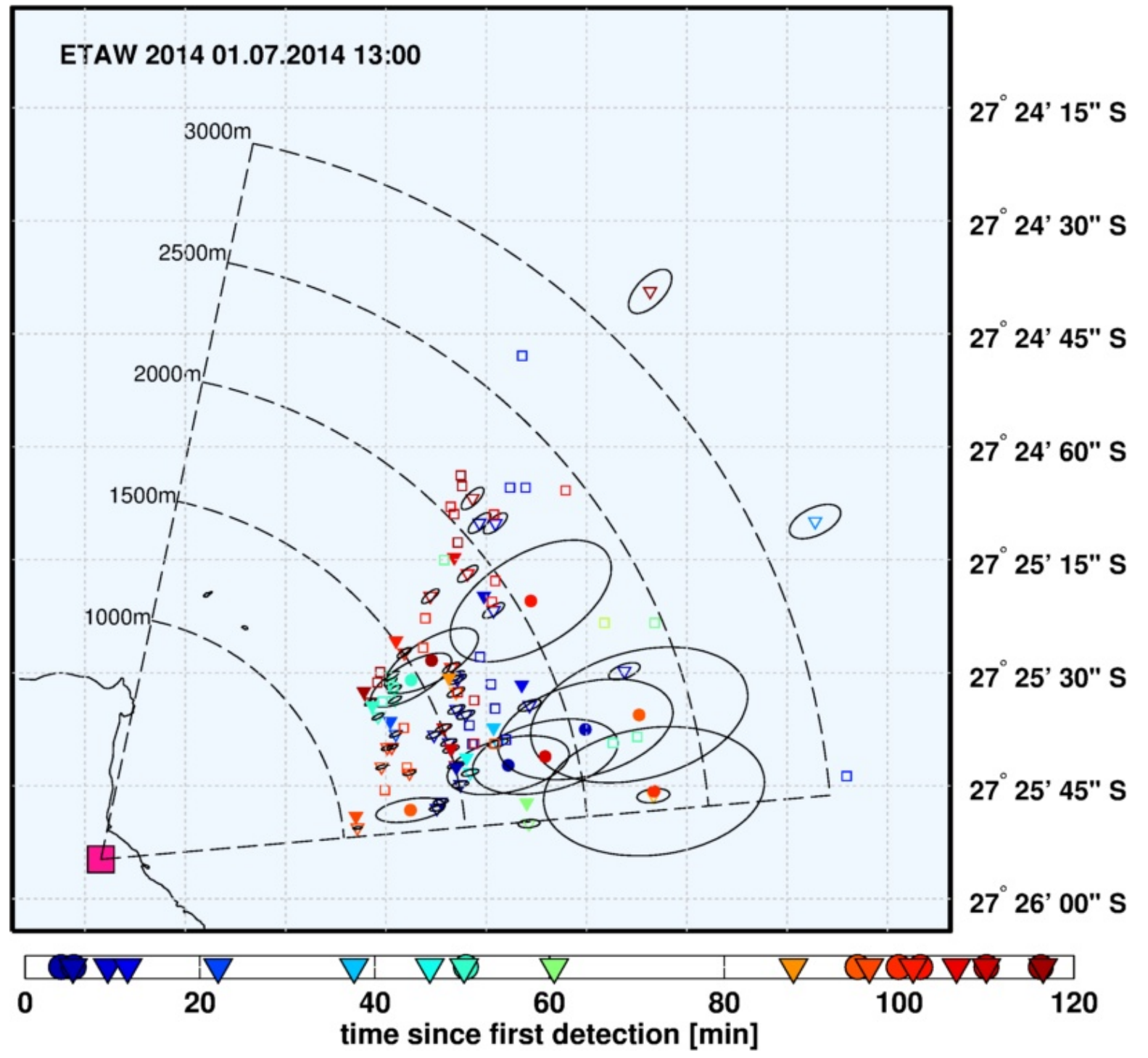

Figure 1. Detected pods by different techniques. Colored dots indicate a detection by the MMO team classified as shutdown decision. Full triangles indicate a detection by the IR team classified as shutdown decision. Open triangles: IR detections of pods which were already detected. Open squares: detections by the theodolite team to obtain ground truth.

\section{IMPACT/APPLICATIONS}

The data acquired so far indicates that thermographic video of the FIRST thermal scanner provides images of suitable contrast to be able to detects the majority of whales present within $2 \mathrm{~km}$ distance of the scanner even under warm water conditions by human screening. The observers subjective 
impression is that observations as nighttime are easier than those at daytime, due to less clutter by reflections of sunlight.

The results imply that FIRST thermal scanner can already be used in a "manual"mode (i.e. real time monitoring by sailors) to improve night-time mitigation measures. The large number of blows identified in the thermographic imagery affirms the feasibility of the development of an autodetections algorithm, i.e. is the ultimate goal of this project.

\section{TRANSITIONS}

Rheinmetall Defence Electronics, Bremen, Germany, has acquired a license of the AWI-developed data acquisition software and current cold-water detection kernel and is marketing the entire system (the FIRST-NAVY sensor head and the AWI-built software components) under the acronym AIMMMS (Automatic Infrared Marine Mammal Mitigation System). However, with the current classification kernel being only applicable to cold water realms, marketing only occurs for polar and sub-polar regions. Any further software developments made during or sponsored by ONR through ETAW do not fall under the current licensing agreement.

\section{RELATED PROJECTS}

We are not conducting any related projects at this time, nor are we aware of any other project perusing this technology being conducted by our colleagues.

We applied for funding of a related test of a dual-band IR camera, which holds the potential of providing an improved $\mathrm{S} / \mathrm{N}$ ratio, however this proposal has been funded due to budget cuts withing the German funding agency BMBF.

\section{PUBLICATIONS}

Note: The papers/reports listed hereinafter describe the current state of development with regard to "cool water" deployments and basically describes the prior knowledge that is being entered into the ETAW (i.e. this) project by AWI.

Zitterbart DP, Kindermann L, Burkhardt E, Boebel O (2013) Automatic Round-the-Clock Detection of Whales for Mitigation from Underwater Noise Impacts. PLoS ONE 8(8): e71217. doi:10.1371/journal.pone.0071217 [published, refereed]

Boebel O., Bombosch A., Burkhardt E., Cammereri A., Kindermann L., Richter S., Zitterbart DP. MAPS: Marine Mammal Perimeter Surveillance. In: Boebel O., editor. The Expedition of the Research Vessel "Polarstern" to the Antarctic in 2012/2013 (ANT-XXIX/2). Bremerhaven: Reports on Polar and Marine Research. [in press]

Burkhardt E., Lanfredi L., Richter S., Boebel O., Kindermann L., Zitterbart DP. MAPS: Marine Mammal Perimeter Surveillance. In: Lucassen M., editor. The Expedition of the Research Vessel "Polarstern" to the Antarctic in 2012 (ANT-XXVIII/4). Bremerhaven: Reports on Polar and Marine Research. 652 , 89 p. 2012 .

Richter S, Müller M, Boebel O, Kindermann L, Zitterbart DP (2012) MAPS: Marine Mammal Perimeter Surveillance. In: Kattner G, editor. The Expedition of the Research Vessel "Polarstern" 
to the Antarctic in 2011/12 (ANT-XXVIII/2). Bremerhaven: Reports on Polar and Marine Research. pp. 56.

Boebel O., Bombosch A., Kindermann L., Zitterbart DP. MAPS: Marine Mammal Perimeter Surveillance In: Fahrbach E, editor. The Expedition of the Research Vessel "Polarstern" to the Antarctic in 2010/2011 (ANT-XXVII/2). Bremerhaven: Reports on Polar and Marine Research, 634, 102 - 110, 2011. (PDF)

Boebel O., Kindermann L., Monsees M., Richter S., Torres Vega M., Zitterbart DP. MAPS: Marine Mammal Perimeter Surveillance In: Bumbke K, editor. The Expedition of the Research Vessel "Polarstern" to the Antarctic in 2010 (ANT-XXVII/1). Bremerhaven: Reports on Polar and Marine Research, 628, 69 - 75, 2011. (PDF)

Zitterbart DP., Kindermann L., Boebel O. MAPS: MAPS: Marine Mammal Perimeter Surveillance In: Gohl K., editor. The Expedition of the Research Vessel "Polarstern" to the Antarctic in 2010 (ANT-XXVI/3). Bremerhaven: Reports on Polar and Marine Research, 617,118 - 124, 2010.

Burkhardt E., Kindermann L., Zitterbart DP., Reimann A. MAPS: Marine Mammal Perimeter Surveillance In: Budeus G., editor. The Expedition of the Research Vessel "Polarstern" to the Antarctic in 2010 (ARK-XXIV/1). Bremerhaven: Reports on Polar and Marine Research, 612, 3134, 2010.

\section{PATENTS}

Note: The patent application below describes the current state of technology and basically describes the prior knowledge that is being entered into the ETAW (i.e. this) project by AWI.

Zitterbart DP, Kindermann L, Boebel O; Method for automatic real-time monitoring of marine mammals, US Patent Application 20,130,070,079, WO Patent Application 2,013,037,344.

\section{HONORS/AWARDS/PRIZES}

Zitterbart DP, AWI, „BRIESE-award for Marine Science”. Briese Schiffahrts GmbH \& Co. KG. 